\title{
DISCAPACIDAD
}

\section{Abordaje de la sexualidad en personas con discapacidad afectadas por una lesión medular. Propuesta de intervención desde la psicomotricidad}

\author{
Diana Isabel Baéz Delvalle
}

\begin{abstract}
Resumen
Introducción: En la búsqueda de soluciones se encontró como la Psicomotricidad favorece la creación de un diálogo corporal y a través de la implicación con todo el cuerpo, permite conseguir objetivos terapéuticos. Las alteraciones en la esfera sexual de las personas con discapacidad de origen neurológico, se recomienda abordarlas aproximadamente a partir de los tres meses, pues en ese periodo de tiempo se puede dar un aprendizaje activo de nuevos patrones de conducta y la modificación de esquemas cognitivos para adaptarse a la nueva realidad corporal y social, donde se produce un nuevo reconocimiento de su propio cuerpo. Después de una lesión medular se produce toda una serie de alteraciones neurológicas, así como también habrá cambios dentro de la esfera sexual.
\end{abstract}

Objetivo: Crear un modelo de intervención desde la Psicomotricidad para integrar la sexualidad como parte importante del proceso de rehabilitación en las personas con discapacidad que han sufrido de una lesión medular.

Material y Método: Se recomienda sesiones grupales y de acuerdo a las necesidades, individuales o de pareja, con una frecuencia de una vez por semana con una duración de 45 minutos, respetando los momentos de descanso según la necesidad de cada usuario. Se llevará a cabo en un espacio de Psicomotricidad, es necesario ser solidario con las peculiaridades del grupo cuando se estructura espacialmente la sala. Dicha disposición debe permitir el acceso.

Los aspectos metodológicos se vinculan con las experiencias acumuladas del profesional que lo interviene. El modelo terapéutico de intervención desde la Psicomotricidad se articula sobre ciertas temáticas abordadas a lo largo de las sesiones, ya sea individualmente, en pequeños grupos o algunas veces en pareja. Debe de ser lo más flexible, globalizado, participativo, con un lenguaje claro y sencillo, adaptado al grupo para pasar posteriormente a una revisión de

\footnotetext{
1. Instituto Guttmann. Universidad Autónoma de Barcelona, España.

Trabajo final de Máster (Tesis). Univ. Autónoma de Barcelona (España). Becada por la Becal. "Don Carlos Antonio López".

E-mail: dianita.baezd@gmail.com

DOI: $10.26885 /$ rcei.foro.2018.38
} 
la misma en cuanto a su estructura y al ajuste de cada persona. Las posibilidades de intervención desde el ámbito psicomotor son muy amplias.

Resultados: La intervención que proponemos es un proceso en la fase de rehabilitación, un modelo desde la Psicomotricidad.

Es así como podremos ir conociendo más sobre nuestra sexualidad, al abrir un espacio a la posibilidad de reconocernos y ser reconocidos desde alternativas nombradas y al experimentarnos desde nuestros placeres, desde nuestros cuerpos que nos da esa capacidad de conocer el placer, el bienestar y los deseos para el disfrute dentro de una esfera sexual.

Conclusiones: La sexualidad empieza en nosotros, al expresarnos, al sentir, en la exploración propia y luego con el otro. Esta experiencia solo puede darse en la medida que somos conscientes de nuestros propios deseos e inquietudes y por medio de la intervención desde la Psicomotricidad, tras una lesión medular, nos ayuda a encontrar nuestra nueva corporeidad, nos ayuda a hacernos cargo de nosotros mismos, de volver a sentir a través del cuerpo.

La inclusión de este modelo o temática puede colaborar con la superación de mitos, tabúes u otras limitaciones que tienen las mismas personas con lesión medular o la sociedad en general.

Este estudio señala el significativo espacio que ocupa la sexualidad y como se puede abordar desde otra disciplina como la Psicomotricidad.

Palabras clave: sexualidad, discapacidad, psicomotricidad.

\section{RefERencias}

Crossman A. R. y Neary D. (2015). Neuroanatomía. Barcelona. Gea consultoría Ed.

Curcoll, M.L., Vidal, J. (1992).Sexualidad y lesión medular. Fundació Institut Guttmann. Barcelona.

Murillo, N. (coord). (2009). Porque tú eres importante! Guía de apoyo para familiares cuidadores de personas con lesión medular o daño cerebral adquirido. Blocs 21. Barcelona: Fundació Institut Guttmann.

Portell, E. (1996). Ayudas técnicas en la discapacidad física. Blocs 8. Barcelona: Fundació Institut Guttmann.

Sassano, M. (2013). La construcción del yo corporal. Buenos Aires. Miño y Dávila Editores. 